\title{
SÍNTESE DE NANOPARTÍCULAS DE OURO UTILIZANDO REDUTORES QUÍMICOS NATURAIS
}

\author{
M. F. COURA, G. ARROYOS e R. C. G. FREM \\ Instituto de Química de Araraquara (UNESP) - Departamento de Química Geral e Inorgânica \\ mariana.coura@hotmail.com
}

\begin{abstract}
RESUMO - Atualmente, a consciência da sociedade em relação ao desenvolvimento sustentável, visando diminuir os prejuízos causados ao meio ambiente pelos processos industriais, está aumentando cada vez mais. Por esse motivo, métodos alternativos de síntese de nanopartículas metálicas estão sendo desenvolvidos, substituindo-se os redutores químicos tóxicos por alternativas menos danosas ao meio ambiente. Baseando-se nesse princípio e em procedimentos clássicos para a síntese de nanopartículas de ouro, esse trabalho desenvolveu um método verde simples de produção desses nanomateriais, utilizando-se extrato de limão em substituição aos agentes redutores tradicionalmente empregados. Quatro diferentes tipos de limão foram utilizados para reduzir um composto precursor de $\mathrm{Au}(\mathrm{III})$, resultando em soluções coloidais avermelhadas que foram caracterizadas via espectroscopia eletrônica e microscopias eletrônicas de varredura e de transmissão. Através do método verde utilizado nesse trabalho, foi possível a obtenção de NPs esféricas e monodispersas com diâmetros de partícula entre 9,48 e 5,07 nm, resultado esse que poderá auxiliar uma gama de pesquisadores da área devido às diversas aplicações que esses materiais apresentam como em catálise, fotônica e bio-imageamento.
\end{abstract}

\section{INTRODUÇÃO}

Existem diversos métodos para a síntese de nanomateriais que usam compostos como borohidreto de sódio, citrato de sódio, ácido ascórbico e outros materiais (tóxicos, na sua grande maioria) como redutores e estabilizantes químicos. Porém, atualmente, a química inorgânica verde vem ganhando destaque, particularmente no que se refere à obtenção de nanopartículas metálicas, em virtude de não agredir o meio ambiente com resíduos tóxicos, ser economicamente eficiente e não necessitar de energia durante os processos de síntese. Dentro dessa perspectiva, a utilização de quatro variedades de limão como redutor químico natural foi investigada como um método não poluente para a produção de nanopartículas de ouro, usando água como solvente.

\subsection{Nanopartículas metálicas}

Nanomaterial é um tipo de material que apresenta dimensões de 1 a $100 \mathrm{~nm}$. Seu tamanho reduzido origina um aumento em sua área superficial por volume, atribuindo-lhe propriedades características (Martins et al., 2012). As nanopartículas metálicas são um tipo de nanomaterial de grande interesse na área de pesquisa atual, em virtude de sua ampla aplicação 
em diversas áreas, desde a catalítica até a médica. Sua síntese envolve, normalmente, alguns tipos de reagentes, como um sal de um determinado metal, uma substância que seja capaz de reduzir esse metal, chamada de agente redutor, e um agente estabilizante para diminuir a tendência dessas nanopartículas em se aglomerarem (Sharma et al., 2012). As nanopartículas também apresentam bandas de absorção características e intensas na região do visível. A aplicação de um campo eletromagnético externo nessas partículas resulta no surgimento de uma oscilação coletiva de elétrons em sua superfície, conhecida como LSPR (Localized Surface Plasmon Resonance). As oscilações e as bandas de absorção correspondentes dependem das propriedades das nanopartículas, como tamanho, forma e ambiente em que se encontram, possibilitando a caracterização por essa técnica espectroscópica (Santos, 2012).

\subsection{Nanopartículas de ouro}

As propriedades ópticas, elétricas, alta estabilidade, boa biocompatibilidade e atividade microbiana das nanopartículas de ouro permitem a sua aplicação como catalisadores, biosensores e marcadores biológicos, além de estarem sendo recentemente usadas em drug delivery e no tratamento de câncer (Siddiqi et al., 2017). No entanto, muitos trabalhos sobre a síntese de ouro coloidal estão presentes na literatura desde 1857, com destaque para o publicado por Faraday e colaboradores onde apresentam algumas análises sobre suas propriedades (Ferreira et al., 2009). Entre os diversos métodos de obtenção de NPs de Au, o procedimento desenvolvido pelo cientista Turkevich, que emprega citrato de sódio como agente redutor e também estabilizante (Santos, 2012), foi utilizado como inspiração para o nosso trabalho, onde foi empregado extrato de limão como fonte do ânion citrato.

\subsection{Química Verde}

Cada vez mais o homem tem se conscientizado em relação à preservação do meio ambiente e devido a essa preocupação, surgiu-se a filosofia da Química Verde, visando modificar os processos químicos para diminuir a poluição que possa ser gerada por eles (Silva et al., 2005). Essa preocupação foi a força-motriz desse trabalho, no qual NPs metálicas foram sintetizadas usando um produto natural em substituição a redutores químicos tóxicos normalmente utilizados. Sob essa mesma perspectiva, a síntese das nanopartículas de ouro utilizou água como solvente e ocorreu sob pressão ambiente e leve aquecimento.

\section{PARTE EXPERIMENTAL}

A fim de retirar qualquer tipo de impureza ou contaminação que pudessem interferir na síntese das NPs de Au, toda a vidraria utilizada no procedimento foi devidamente deixada em contato com água régia por 10 minutos e, posteriormente, lavada com água deionizada.

\subsection{Preparação das soluções redutoras}

Para realizar o preparo das soluções redutoras, extraiu-se, primeiramente, o suco de cada um dos quatro tipos de limão (tahiti, cravo, siciliano e galego), separadamente, peneirando-os para que as partículas maiores presentes nas soluções ficassem retidas. Para cada um dos extratos, realizou-se uma centrifugação durante 10 minutos a $20^{\circ} \mathrm{C}$ e $13000 \mathrm{rpm}$. 
Em seguida, descartou-se o material sólido obtido e, com o auxílio de uma bomba à vácuo, filtrou-se duas vezes cada um dos sobrenadantes, colocando-os em béqueres separados. Por fim, realizou-se o ajuste de $\mathrm{pH}$ de cada uma das soluções, utilizando-se um pHmetro e empregando-se hidróxido de sódio de concentração $1 \mathrm{~mol} / \mathrm{L}$, até que o valor de $\mathrm{pH}$ de cada uma das soluções fosse de, aproximadamente, 6,2.

\subsection{Síntese das nanopartículas de ouro (NPAu tahiti, NPAu cravo, NPAu siciliano e NPAu galego)}

Primeiramente, colocou-se $1 \mathrm{ml}$ de solução de $\mathrm{HAuCl}_{4}\left(10^{-3} \mathrm{~mol} / \mathrm{L}\right)$ em um béquer, aquecendo-o a $100^{\circ} \mathrm{C}$ e mantendo-o sob agitação em um agitador magnético. Depois de decorridos três minutos, desligou-se o aquecimento, mantendo-se apenas a agitação, e adicionou 2,5 ml da solução redutora de um dos tipos de limão. Observou-se uma mudança instantânea na coloração da solução, passando de amarelo, cor da solução do ácido cloroáurico, para vermelha, coloração característica de NPs de Au. Manteve-se a solução sob agitação por 10 minutos e armazenou-se o material obtido sob refrigeração. Realizou-se o mesmo procedimento para os outros tipos de limão, obtendo-se resultados semelhantes.

\section{RESULTADOS E DISCUSSÃO}

As nanopartículas de ouro sintetizadas com os diferentes extratos de limão (NPAu tahiti, NPAu cravo, NPAu siciliano e NPAu galego) foram submetidas à análise via espectroscopia LSPR. As propriedades ópticas típicas das NPs são conferidas pela interação da luz com elétrons sobre a superfície. Em um determinado comprimento de onda da luz, a oscilação coletiva dos elétrons sobre sua superfície causa um fenômeno conhecido como ressonância de plasmon de superfície localizado, resultando em uma forte extinção da luz (via absorção e espalhamento). Entre outros fatores, a frequência característica da luz onde isso ocorre é fortemente dependente do tamanho e do estado de aglomeração das nanopartículas de ouro. Os espectros eletrônicos obtidos para as quatro amostras sintetizadas usando diferentes extratos naturais como agentes redutores de íons $\mathrm{Au}(\mathrm{III})$ estão apresentados na Figura 1.

Figura 1: Espectros eletrônicos das NPs de Au sintetizadas com diferentes extratos de limão.

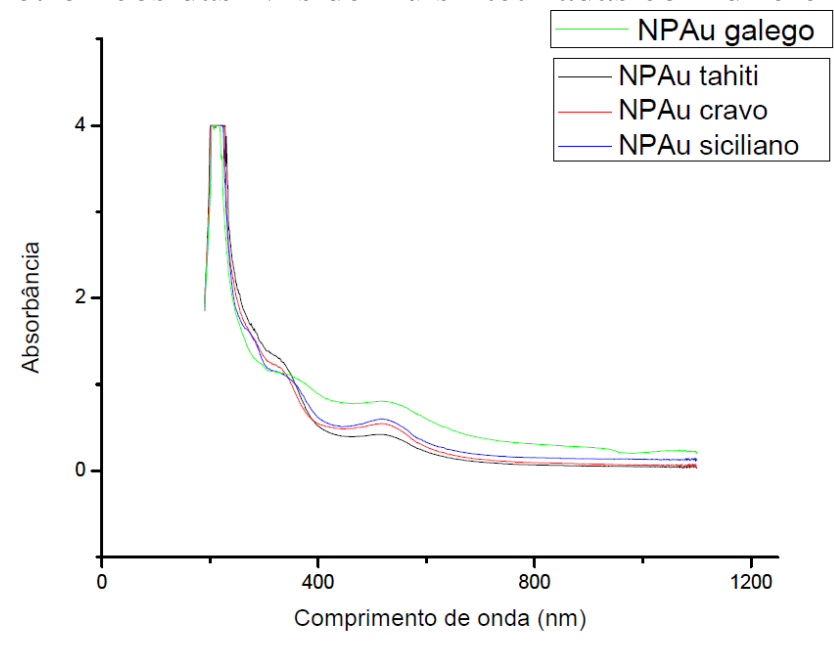


Como pode ser observado, os diferentes tipos de limão conduziram invariavelmente à formação de nanopartículas de ouro de mesmo tamanho. O comprimento de onda do pico SPR foi observado próximo a $516 \mathrm{~nm}$ para todas as amostras, característico de nanopartículas avermelhadas de ouro que apresentam tamanho entre 3 e $10 \mathrm{~nm}$ (Yue et al., 2016). Além disso, a ausência de uma segunda banda de ressonância de plasmon próxima a $650 \mathrm{~nm}$, revelou também que as NPS encontram-se monodispersas. De fato, esses resultados puderam ser confirmados por microscopia eletrônica de varredura, cujas imagens estão ilustradas nas Figuras 2-5 para as nanopartículas de ouro obtidas com os limões tahiti, cravo, siciliano e galego, respectivamente.

Figura 2: Imagem MEV e estimativa de tamanho das nanopartículas NPAu tahiti.

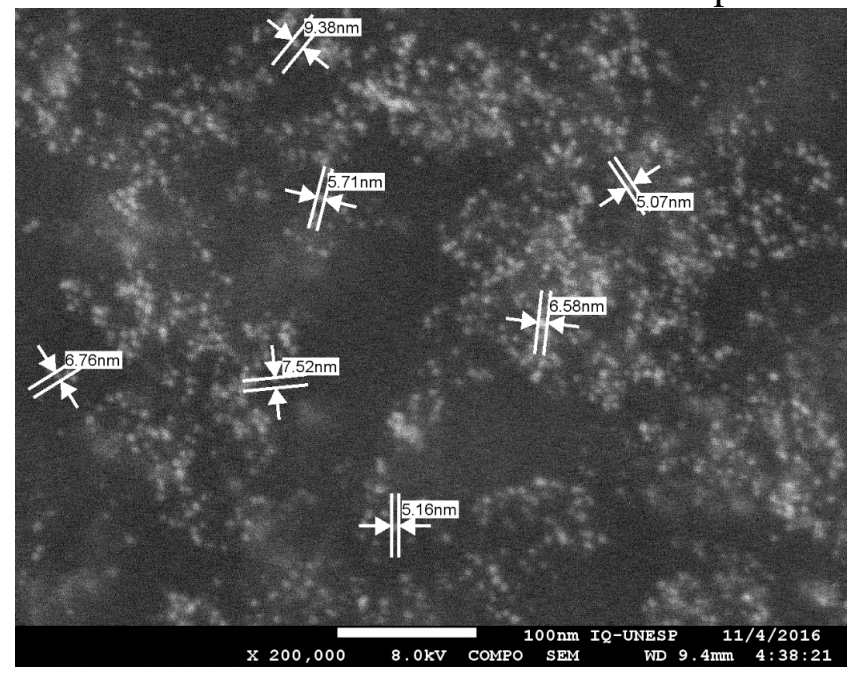

Figura 3: Imagem MEV da amostra NPAu cravo e estimativa do tamanho de suas partículas.

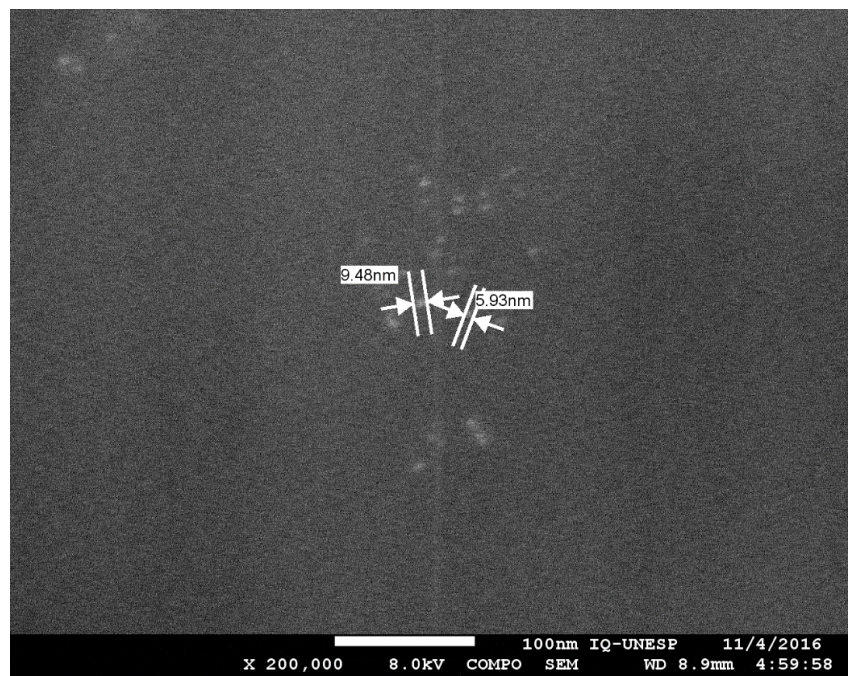


Figura 4: Imagem MEV da amostra NPAu siciliano e seus tamanhos.

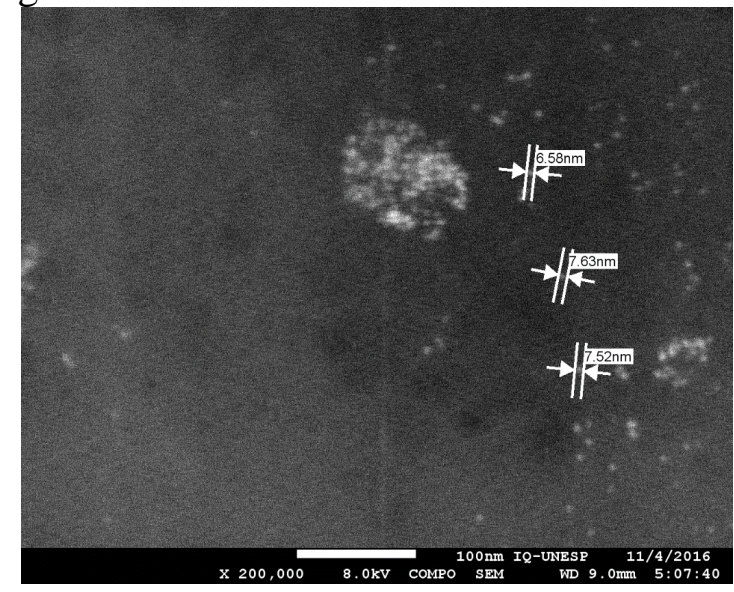

Figura 5: Imagem MEV das nanopartículas NPAu galego com seus tamanhos estimados.

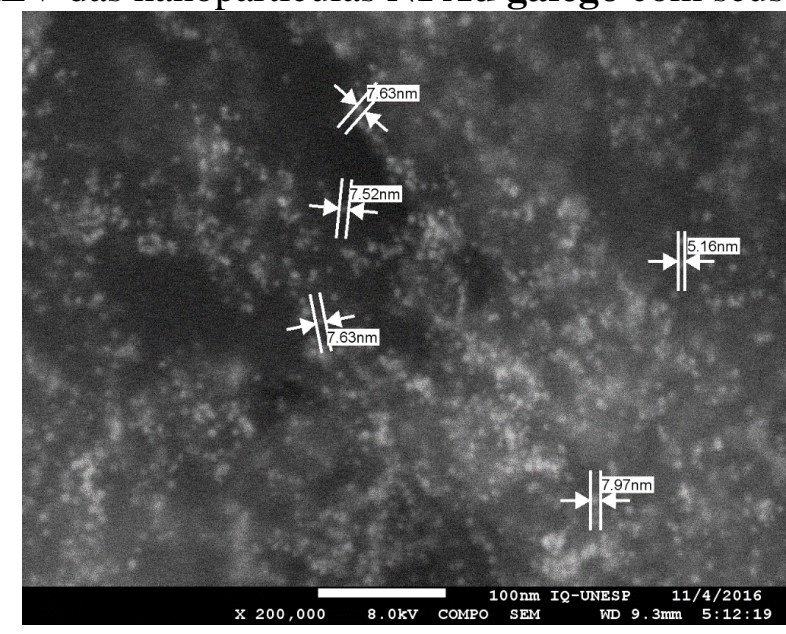

Alta densidade eletrônica sobre as nanopartículas de ouro (amostra NPAu tahiti) assim como uma considerável homogeneidade de suas forma e tamanho tornaram-se evidente sob o microscópio eletrônico de transmissão (ver Figura 6).

Figura 6: Imagens MET da amostra NPAu tahiti.

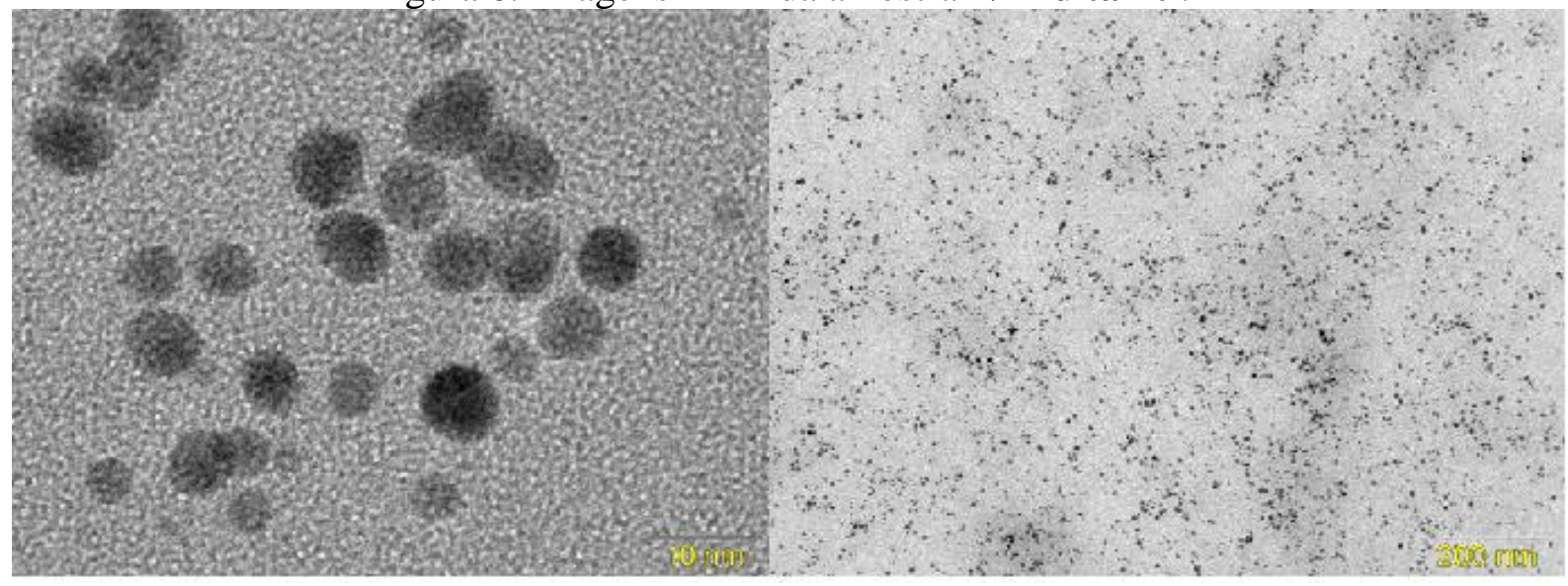




\section{CONCLUSÕES}

Neste trabalho, nanopartículas de ouro foram sintetizadas através de um método verde, usando água como solvente (pH próximo a 6,0) e extratos de limão como agente redutor. A partir das análises realizadas, pode ser constatado que as nanopartículas sintetizadas com os diferentes tipos de limão são semelhantes, já que todas apresentaram coloração avermelhada, são relativamente esféricas e com tamanhos muito pequenos $(9,5-5,1 \mathrm{~nm})$, comprovando que, de fato, o ácido cítrico (os limões utilizados possuem quantidades similares do mesmo) é $\mathrm{o}$ agente redutor do processo.

\section{NOMENCLATURA}

NPAu cravo = Nanopartículas de ouro sintetizadas com o limão cravo;

NPAu galego = Nanopartículas de ouro preparadas com o limão galego;

NPAu siciliano = Nanopartículas de ouro sintetizadas com o limão siciliano;

NPAu tahiti = Nanopartículas de ouro obtidas utilizando o limão tahiti como redutor.

\section{REFERÊNCIAS}

FERREIRA, H. S.; RANGEL, M. C. Nanotecnologia: aspectos gerais e potencial de aplicação em catálise. Q. Nova, vol. 32, n. 7, p. 1860-1870, 2009.

MARTINS, M. A.; TRINDADE, T. Os nanomateriais e a descoberta de novos mundos na bancada do químico. Q. Nova, vol. 35, n. 7, p. 1434-1446, 2012.

SANTOS, M. V. Nanocompósitos baseados em celulose bacteriana para aplicações ópticas. 2012. Dissertação (Mestrado) - Universidade Estadual Paulista "Júlio de Mesquita Filho", Araraquara, 2012.

SHARMA, R.K.; GULATI, S.; MEHTA, S. Preparation of gold nanoparticles using tea: A Green Chemistry Experiment. J. Chem. Educ., v.89, p. 1316-1318, 2012.

SIDDIQI, K. S.; HUSEN, A. Recent advances in plant-mediated engineered gold nanoparticles and their application in biological system. J. Trace Elem. Medicine and Biology, v. 40, p. 10-23, 2017.

SILVA, F. M. da; LACERDA, P.S.B. de; JUNIOR, J.J. Desenvolvimento sustentável e química verde. $Q$. Nova, v.28, n.1, p.103-110, 2005.

YUE, G.; et al. Gold nanoparticles as sensors in the colorimetric and fluorescence detection of chemical warface agents. Coord. Chem. Rev., v. 311, p. 75-84, 2016. 